\title{
Keamanan Basis Data pada Perancangan Sistem Kepakaran Prestasi SMAN dikota Surakarta
}

\author{
Robi Wariyanto Abdullah*, Sri Wulandari ${ }^{2}$, Fendy Prasetyo Nugroho ${ }^{3}$ \\ ${ }^{1,3}$ Program Magister Teknik Informatika Universitas AMIKOM Yogyakarta, ${ }^{2}$ STIE “AUB” \\ Surakarta \\ E-mail : ${ }^{* 1}$ robiwariyanto@gmail.com, ${ }^{2}$ oel and@yahoo.com, ${ }^{3}$ vendyscenter@yahoo.com
}

\begin{abstract}
Abstrak
SMA Negeri di Kota Surakarta memiliki prestasi yang berbeda-beda. Untuk melihat prestasi tersebut maka diperlukan adanya suatu sistem kepakaran yang dapat memberikan informasi tentang prestasi yang dimiliki oleh sekolah kepada masyarakat, baik prestasi siswa maupun prestasi guru atau tenaga pendidik. Pada Perancangan sistem kepakaran prestasi sekolah diperlukan pula perancangan basis data sistem tersebut. Seringkali pengembang tidak memperhatikan segi keamanan data pada basis data saat merancang sebuah sistem. Perancangan sistem dibuat kedalam konsep pemetaan data, KonteksDiagram, dan Relasi tabel. Penelitian ini juga akan membahas tentang pembatasan hak akses basis data pada MySQL yang berguna untuk membatasi pengguna dalam mengakses basis data. Berdasarkan rancangan tersebut maka penulis menyajikan suatu perancangan sistem kepakaran prestasi sekolah berbasis web sebagai sarana informasi prestasi SMA Negeri di kota Surakarta. Metode dalam penelitian ini meliputi tinjauan pustaka, pengumpulan data, merancang sistem kepakaran prestasi,dan merancang serta prosedur keamanan basis data sistem kepakaran di SMAN Surakarta. Hasil dari penelitian ini adalah sistem kepakaran prestasi sekolah di SMAN Surakarta berdasarkan ketegori prestasi, tingkat prestasi, dan tahun prestasi serta rancangan basis data sistem kepakaran prestasi sekolah dengan memperhatikan keamanan basis data.
\end{abstract}

Kata Kunci-Kepakaran, Prestasi, Basis Data, MySQL

\begin{abstract}
Stete high schools in Surakarta City have different achievements. To see these achievements, it is necessary to have an expert system that provides information about the achievements of the school to the community, both student achievement and the achievements of teachers or educators. In designing the expertise system of school achievement, it is also necessary to design the database system. Often developers don't pay attention to data security in the database when designing a system. System design is made into the concept of data mapping, Context Diagrams, and Table Relations. This research will also discuss restrictions on database access rights in MYSQL which is useful to restrict users from accessing the database. Based on the design, the writer presents a web-based school achievement expertise design system as a means of information on the achievements of public high schools in the city of Surakarta. The method in this study covers literature review, data collection, designing achievement expertise systems, and designing and security procedures for the expert system database at Surakarta Senior High School. The results of this study are the system of school achievement expertise in Surakarta Senior High School based on the categories of achievement, level of achievement, and year of achievement as well as the design database of the school achievement system with regard to database security.
\end{abstract}

Keywords—Expertise, Achievement, Database, MySQL 


\section{PENDAHULUAN}

Penerapan teknologi informasi sangat memberikan kontribusi yang cukup baik dalamkelancaran aktivitas di dunia pendidikan. Penggunaan teknologi informasi yang tepat dapat membantu dalammengambil keputusan dimana penyimpanan data telah didukung oleh salah satu komponenpenting dari teknologi informasi yaitu basis data [1].

Sistem kepakaran prestasi sekolah adalah suatu sistem untuk menampung, melakukan pencarian informasi dan mengetahui statistik dari prestasi suatu sekolah. Prestasi sekolah yang ditampilkan dapat dilihat berdasarkan prestasi sekolah itu sendiri, prestasi tenaga pendidik maupun prestasi siswa.

Penentuan kepakaran suatu sekolah harus bersifat objektif berdasarkan parameter yang telah ditentukan. Parameter tersebut dapat berupa akreditasi sekolah, prestasi tenaga pendidik maupun prestasi dari sekolah itu sendiri. Penentuan sekolah berdasarkan kepakaran prestasi sekolah dengan melihat beberapa parameter yang dipakai. Sistem kepakaran prestasi sekolah diharapkan dapat membantu mengetahui perbandingan kepakaran prestasi semua sekolah yang ada.

Beberapa penelitian yang berkaitan dengan perancangan sistem kepakaran hanya dibahas tentang sistem kepakaran dari sisi programnya, namun belum dibahas mengenai keamanan basis datanya[2] [3] [4].

Sebuah sistem informasi tidak lepas dari basis data. Begitu juga pada sistem kepakaran tidak lepas dari adanya basis data. Perancangan basis data pada sistem kepakaran akan ditekankan pada role access system dengan menggunakan basis data MySQL yang disesuaikan dengan role access setiap acount user yang akan dibuat pada basis data. Hal ini bertujuan untuk meminimalkan kesalahan pengolahan data melalui basisdata $M y S Q L$ pada saat melihat hasil pencarian sistem kepakaran prestasi sekolah. Perancangan basis data pada sistem kepakaran dan sistem keamanan pada basis datanya berkaitan dengan beberapa penelitian [5] [6] [7] [8].

Penelitian ini akan membahas tentang rancangan sistem kepakaran prestasi sekolah SMANdi Kota Surakarta dan perancangan basis data dari sistem tersebut dengan memperhatikan parameter dari prestasi sekolah baik dari tenaga pendidik dan prestasi siswa.

\section{METODE PENELITIAN}

Penelitian ini menjelaskan bagaimana merancang sistem kepakaran prestasi pada SMAN di Kota Surakarta dan merancang basis data $M y S Q L$ sistem tersebut dengan role hak akses tiap account user yang telah ditentukan. Adapun alur penelitian ini adalah:

1. Studi literatur

Studi literatur dengan mempelajari teori-teori berdasarkan artikel yang berkaitan dengan penelitian. Teori-teori yang berkaitan dengan penelitian ini adalah sistem kepakaran, perancangan basis data, dan prosedur kemanan basis data.

2. Pengumpulan data

Pengumpulan data dengan melakukan observasi pada website kemendikbud http://sekolah.data.kemendikbud.go.id/. Data yang diperoleh merupakan data sekunder, yaitu data prestasi siswa dan tenaga pendidik.

3. Perancangan sistem kepakaran

Berdasarkan data yang diperoleh maka dibuat rancangan sistem kepakaran prestasi sekolah pada SMAN di Kota Surakarta. Rancangan tersebut meliputi peta situs sistem kepakaran, framework pencarian serta statistik prestasi, dan interface hasil pencarian.

4. Perancangan dan prosedur keamanan basis data sistem kepakaran

Membuat rancangan basis data berdasarkan rancangan sistem kepakaran yang telah dibuat. Perancangan basis data dengan membuat tabel-tabel yang dibutuhkan dan membuat relasi antar tabel. Setelah rancangan basis data dibuat selanjutnya menentukan prosedur untuk keamanan basis data berdasarkan role hak akses tiap account user.

5. Hasil penelitian 
Hasil penelitian ini adalah sistem kepakaran prestasi sekolah dan perancangan serta prosedur kemanan basis data pada sistem kepakaran prestasi sekolah pada SMAN di Kota Surakarta.

\section{HASIL DAN PEMBAHASAN}

Penelitian ini membahas tentang perancangan sistem kepakaran prestasi SMAN di Kota Surakarta, yaitu merancang sistem kepakaran, pemodelan proses, merancang basis data dan desain sistem kepakaran prestasi sekolah. Dalam penelitian ini penulis mengambil data dari website kemendikbud http://sekolah.data.kemdikbud.go.id/ yang berguna untuk diolah kedalam sistem kepakaran. Berdasarkan data tersebut maka penulis merancang pemetaan site sistem kepakaran prestasi sekolah yang meliputi peta situs sistem kepakaran seperti pada Gambar 1.

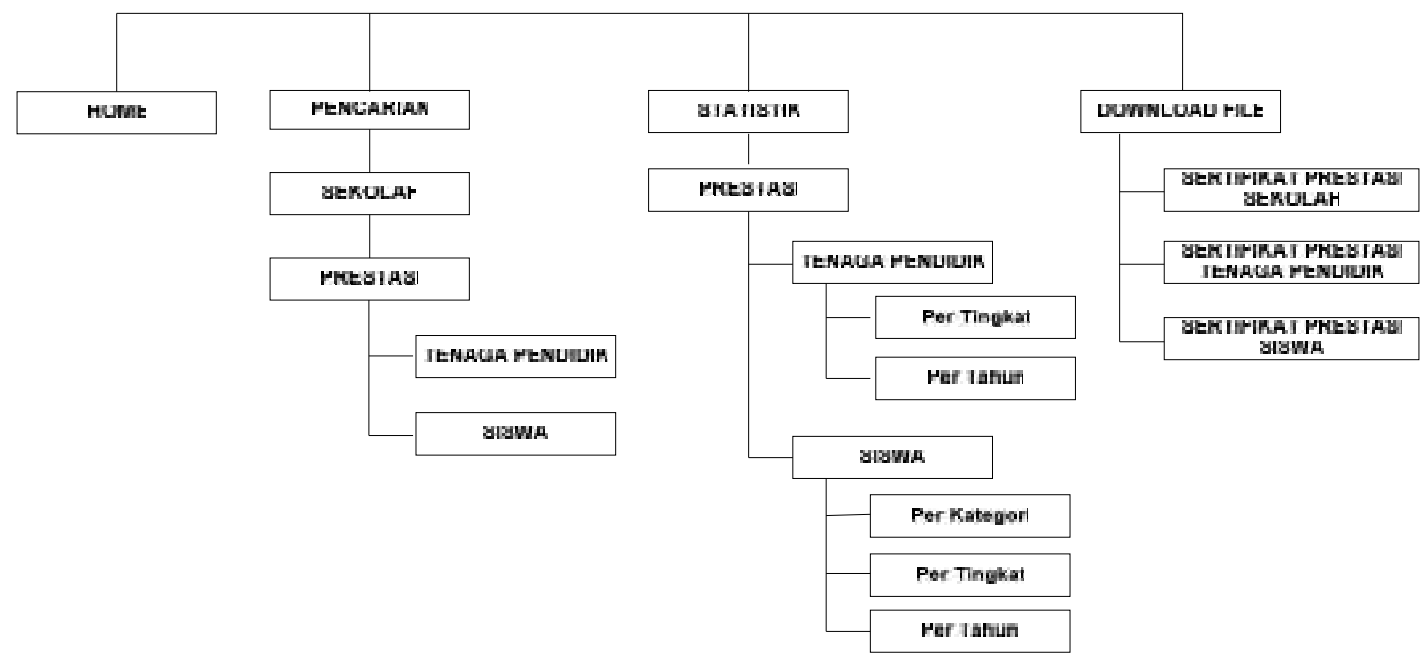

Gambar 1. Diagram Peta Situs Sistem Kepakaran

Adapun framework menu utama pada sistem kepakaran prestasi sekolah terdiri dari : pencarian, statistis dan unduh file framework statistik dapat dilihat pada Gambar 2.

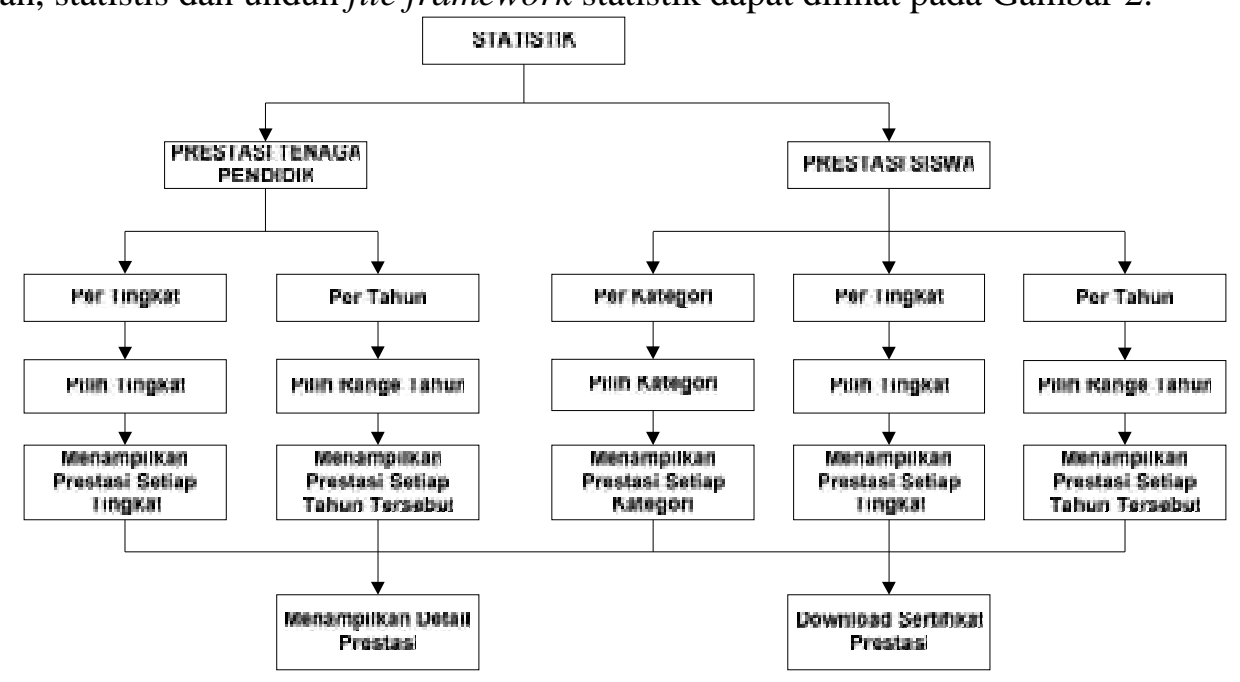

Gambar 2. Diagram Framework Statistik Prestasi

Berdasarkan peta situs pemetaan kepakaran dan framework system yang telah dirancang diatas dapat dilihat bahwa dalam sistem terdapat fitur pencarian data sekolah, perbandingan sekolah, pencarian prestasi sekolah dan statistik sekolah maupun fitur untuk mengunduh bukti 
prestasi sekolah. Berdasarkan pemetaan sistem kepakaran yang telah dibuat maka dapat dirancang pemodelan proses seperti pada Gambar 3 sebagai berikut.

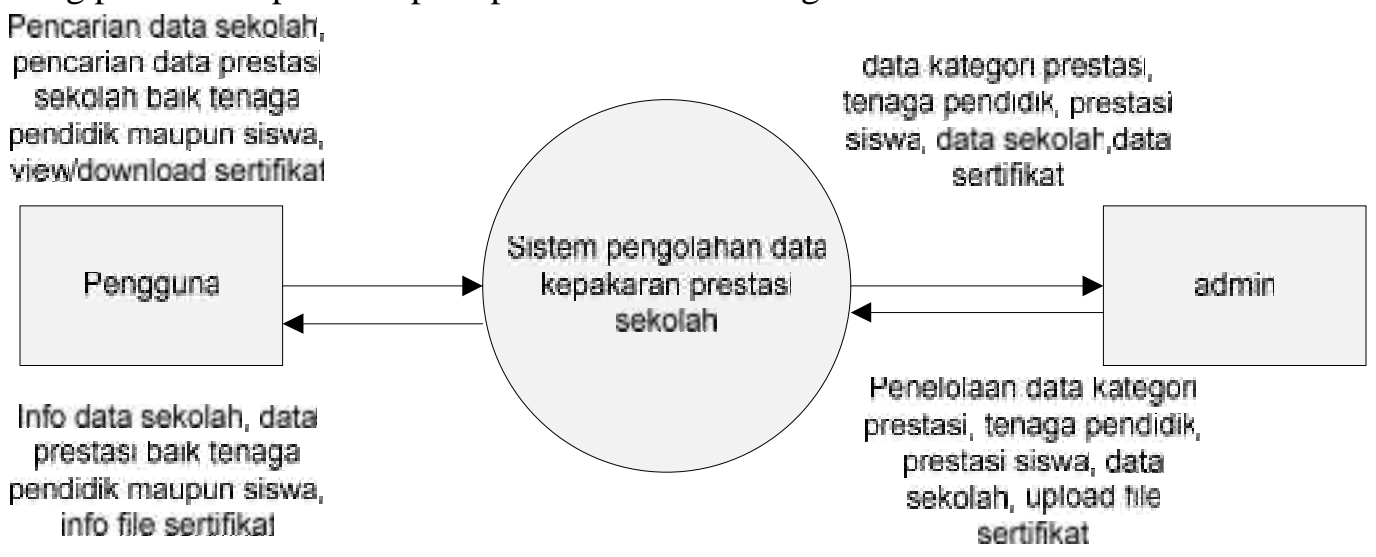

Gambar 3. Contect Diagram Sistem Kepakaran

Pada perancangan sistem kepakaran tersebut dapat dibuat rancangan basis data dengan merelasikan antar tabel [9] [10]. Basis data pada rancangan tersebut membutuhkan beberapa tabel diantaranya tabel_prestasi, kategori_prestasi, tabel_sekolah, file_download, siswa, kota, pendidik, admin. Relasi antartabelyang diperlukan dalam basis data kepakaran ditunjukkan pada Gambar 4.

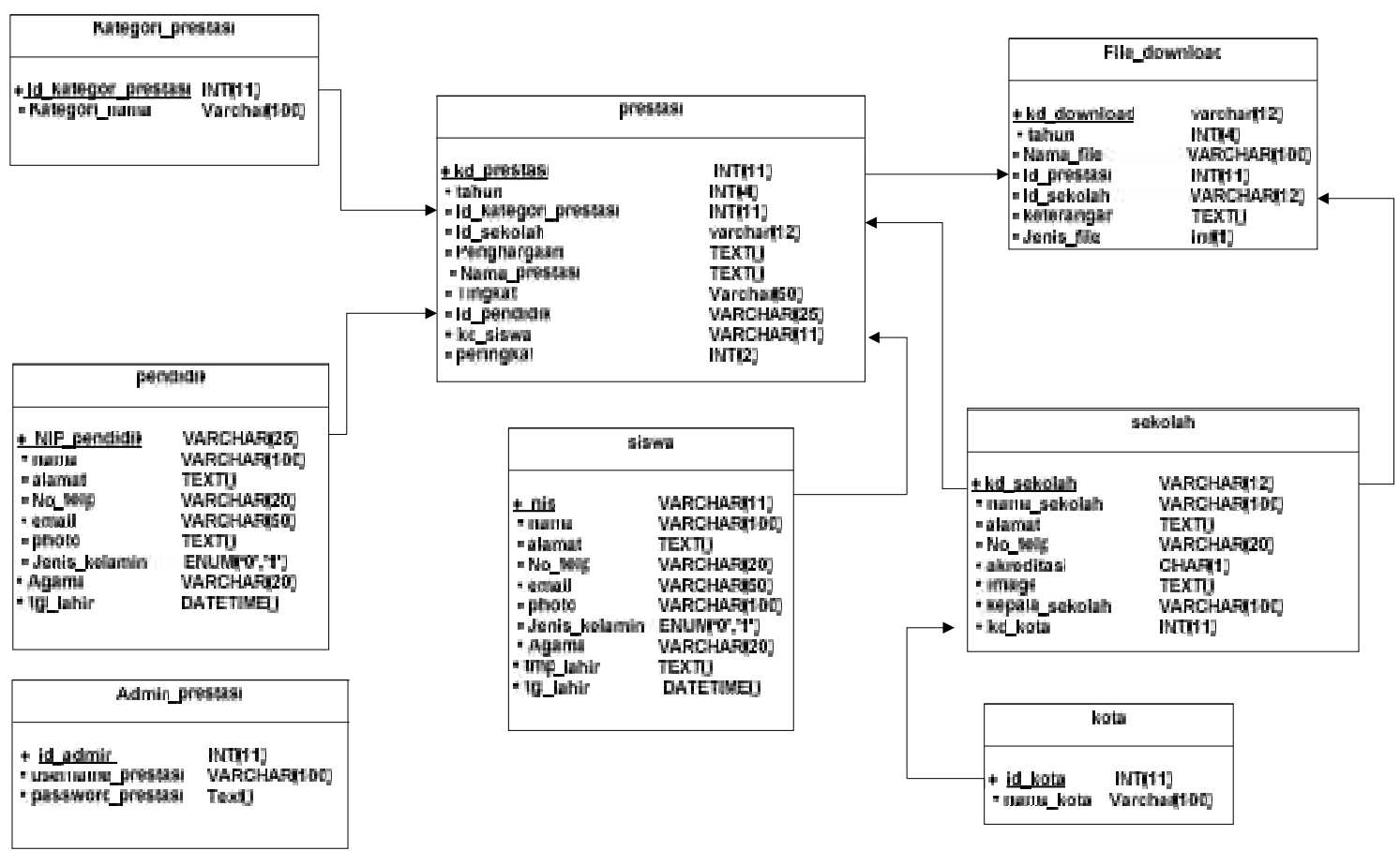

Gambar 4. Relasi Basis Data Kepakaran

Berdasarkan relasi tabel pada Gambar 4 maka perlu dibuat suatu constrain foreign key agar inputan data yang saling berelasi tidak terjadi kesalahan dari sisi basis data maupun dari sisi program atau sistem kepakaran. Salah satu contoh yang penulis berikan yaitu foreignkey pada tabel prestasiyang berelasi dengan tabel sekolah.

Berdasarkan constrain foreign key yang dibuat seperti Gambar 5 jika penulis ujikan input data melalui SQL dengan mengisi data id_sekolahpada tabel prestasiyang tidak terdapat pada tabel sekolahmaka data tidak akan tersimpan dan akan menampilkan pesan kesalahan seperti yang ditunjukkan pada Gambar 6. 


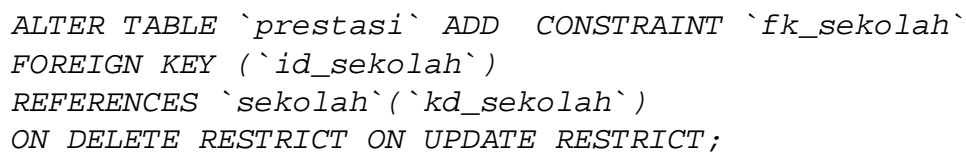

Gambar 5. Constrain Tabel Prestasi

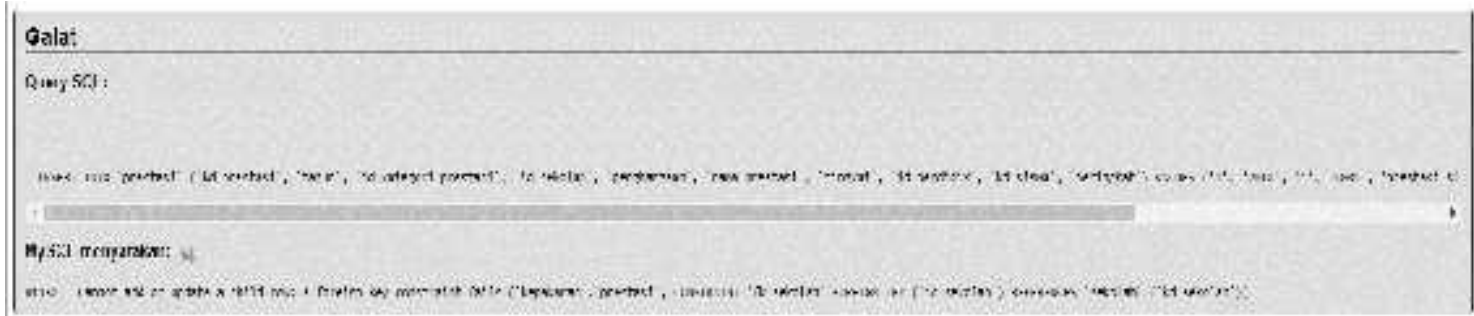

Gambar 6. Pesan Kesalahan Insert Data

Pada perancangan data basis data sistem kepakaran juga perlu diperhatikan format inputan yang harus dipenuhi agar yang dimasukkan valid baik dari sisi program maupun dari basis data.Gambar 7 menunjukkanpembuatan trigger untuk menvalidasi inputan e-mail pada tabel pendidik dari sisi basis data yang digunakan.

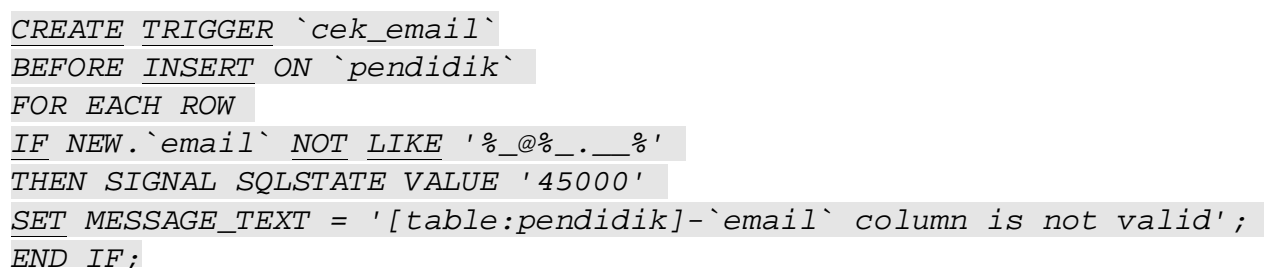

Gambar 7. Triger Valid Format E-Mail

Selain constrain foreign key perancangan basis data kepakaran juga harus memperhatikan hak akses atau roleaccess pengguna dalam mengakses basisdatakepakaran sehingga keamanan data dapat diminimalisir jika terjadi adanya penyalahgunaan data yang tidak diinginkan.

Dalam perancangan sistem kepakaran penulis merancang dua pengguna akses ke basis data kapakaran diantaranya hak akses pengguna(user) dan hak akses admin dimana hak akses masing-masing role memiliki akses yang berbeda seperti ditunjukkan pada Tabel 1.

Tabel 1. Hak Akses Role Basis Data Kepakaran

\begin{tabular}{|l|c|c|c|c|c|c|c|c|}
\hline \multirow{2}{*}{ TABEL } & \multicolumn{2}{c|}{ SELECT } & \multicolumn{2}{c|}{ INSERT } & \multicolumn{2}{c|}{ UPDATE } & \multicolumn{2}{c|}{ DELETE } \\
\cline { 2 - 10 } & User & Admin & User & Admin & User & Admin & User & Admin \\
\hline Tabel prestasi & $\sqrt{ }$ & $\sqrt{ }$ & $\mathrm{x}$ & $\sqrt{ }$ & $\mathrm{x}$ & $\sqrt{ }$ & $\mathrm{x}$ & $\sqrt{ }$ \\
\hline Tabel sekolah & $\sqrt{ }$ & $\sqrt{ }$ & $\mathrm{x}$ & $\sqrt{ }$ & $\mathrm{x}$ & $\sqrt{ }$ & $\mathrm{x}$ & $\sqrt{ }$ \\
\hline Tabel siswa & $\sqrt{ }$ & $\sqrt{ }$ & $\mathrm{x}$ & $\sqrt{ }$ & $\mathrm{x}$ & $\sqrt{ }$ & $\mathrm{x}$ & $\sqrt{ }$ \\
\hline Tabel pendidik & $\sqrt{ }$ & $\sqrt{ }$ & $\mathrm{x}$ & $\sqrt{ }$ & $\mathrm{x}$ & $\sqrt{ }$ & $\mathrm{x}$ & $\sqrt{ }$ \\
\hline Tabel kota & $\sqrt{ }$ & $\sqrt{ }$ & $\mathrm{x}$ & $\sqrt{ }$ & $\mathrm{x}$ & $\sqrt{ }$ & $\mathrm{x}$ & $\sqrt{ }$ \\
\hline Tabel file_download & $\sqrt{ }$ & $\sqrt{ }$ & $\mathrm{x}$ & $\sqrt{ }$ & $\mathrm{x}$ & $\sqrt{ }$ & $\mathrm{x}$ & $\sqrt{ }$ \\
\hline Tabel kategori_prestasi & $\sqrt{ }$ & $\sqrt{ }$ & $\mathrm{x}$ & $\sqrt{ }$ & $\mathrm{x}$ & $\sqrt{ }$ & $\mathrm{x}$ & $\sqrt{ }$ \\
\hline Tabel admin_prestasi & $\mathrm{x}$ & $\mathrm{x}$ & $\mathrm{x}$ & $\sqrt{ }$ & $\mathrm{x}$ & $\sqrt{ }$ & $\mathrm{x}$ & $\sqrt{ }$ \\
\hline
\end{tabular}

Berdasarkan hak akses yang diberikan oleh user:pengguna_pakarmaka ketika pengguna akses ke basis data dengan user pengguna_pakar tabel admin_prestasitidak akan dapat tampil dan tidak dapat diakses seperti pada Gambar 8 karena pengguna_pakartidak diberikan hak 
apapun untuk akses tabel admin_prestasi. Sedangkan jika admin masuk dengan user admin_pakarmaka tabel admin_prestasidapat tampil seperti pada Gambar 9 dan dapat diakses oleh user admin_pakartersebut.

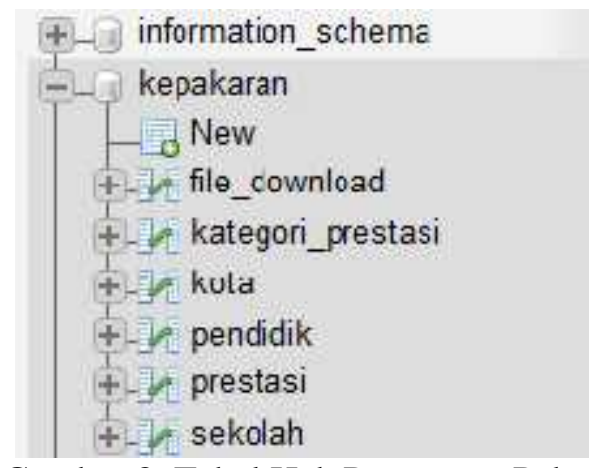

Gambar 8. Tabel Hak Pengguna_Pakar

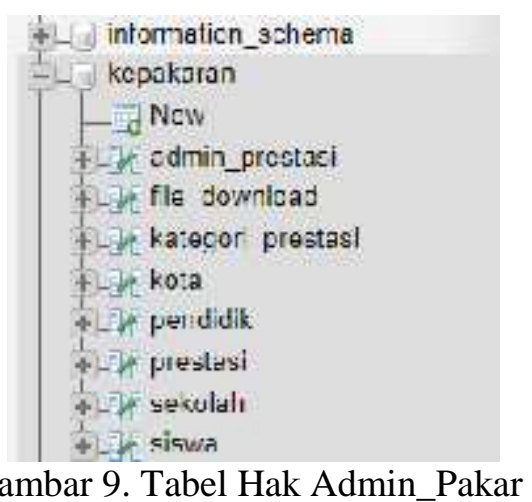

Gambar 9. Tabel Hak Admin_Pakar

Berdasarkan hak akses yang sudah didefinisikan pada tabel 1jika pengguna menggunakan user pengguna_pakarmaka user tersebut hanya akan dapat melihat data dan tidak dapat melakukan penambahan, update dan hapus data. Jika pengguna menggunakan user pengguna_pakar melakukan penambahan, update maupun hapus data melalui MySQL maka akan menampilkan pesan kesalahan seperti pada Gambar 10.

Jika diimplementasikan melalui sistem juga tidak akan berjalan, berbeda jika user yang digunakan dengan admin_pakardimana hak akses pada tabel memiliki semua hak akses sehingga jika dilakukan pengelolaan data baik penambahan, update data, maupun hapus data akan dapat dilakukan. Dengan dirancangnya user hak akses pengelolaan data kapakaran prestasi sekolah lebih dapat terkendali sesuai dengan hak akses yang dirancang baik dari sisi basis data maupun dari sisi sistem atau program.

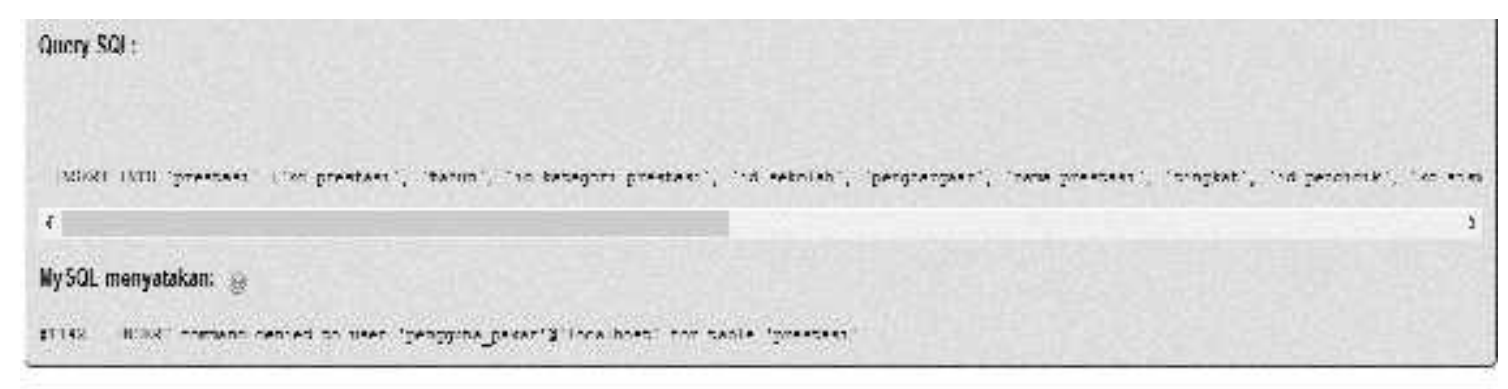

Gambar 10. Pesan Kesalahan Tidak Punya Hak Insert, Update Dan Delete

Berdasarkan site pemetaan kepakaran sekolah, pemodelan proses, dan relasi tabel yang telah dirancang diatas maka penulis dapat mendesain user interface system perbandingan kepakaran sekolah yang akan dikembangkan yang dapat diakses oleh orang tua calon siswa, seperti pada Gambar 19. 


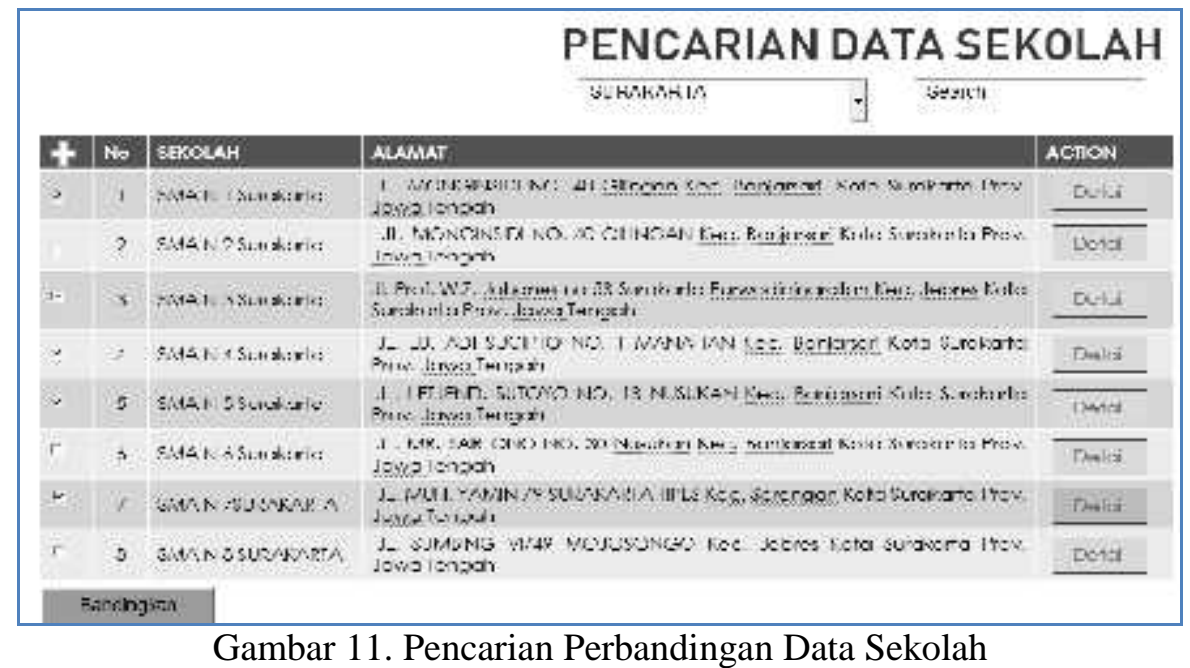

Dari interface pencarian sekolah diatas maka pengguna dapat membandingkan kepakaran sekolah yang dipilih sehingga akan menampilkan informasi kepakaran detail sekolah sebagai masukan informasi untuk pemilihan sekolah yang diminati dan pemilihan siswa berprestasi untuk didelegasikan pada olimpiade sains dan teknologi. Hasil perbandingan pencarian akan terlihat seperti Gambar 12.

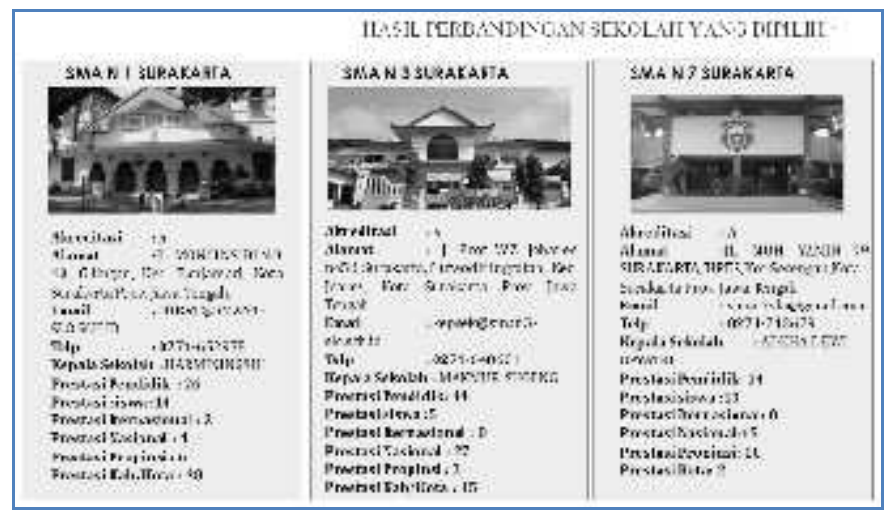

Gambar 12. Hasil Perbandingan Kepakaran SMA

Dari rancangan interface detail sekolah diatas dapat juga untuk mengetahui lebih detail kepakaran tenaga pendidik dengan klik nama tenaga pendidik. Selain itu pengguna juga dapat melihat atau mengunduh sertifikat akreditasi sekolah maupun sertifikat prestasi tenaga pendidik maupun siswa.

Berikut ini tampilan data statistik prestasi semua sekolah SMANdi kota Surakarta dapat dilihat pada Gambar 13 sebagai berikut.

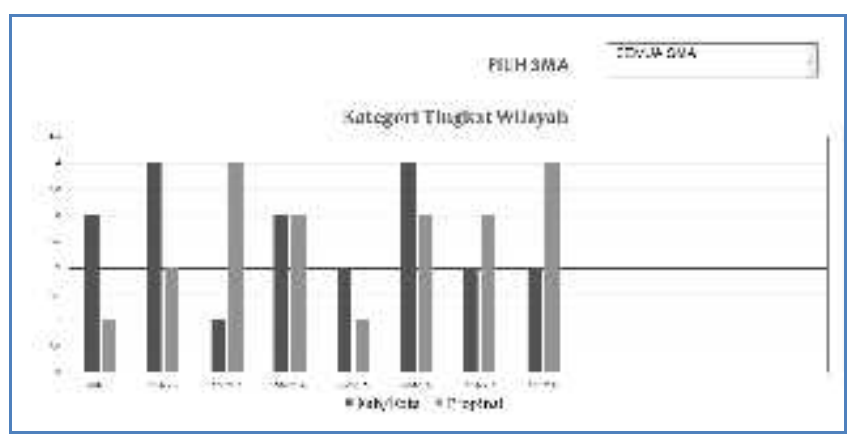

Gambar 13. Interface Statistik Prestasi Sekolah Tingkat Prestasi 
Pada interface statistik dipilih sekolah yang akan dilihat dan akan menampilkan grafik seperti pada Gambar 13. Dari tampilan grafik yang muncul dapat mengetahui detail prestasi sekolah dengan klik diagram batang pada grafik sesuai dengan kategori yang tampil sehingga akan menampilkan detail informasi prestasi seperti pada Gambar 14.

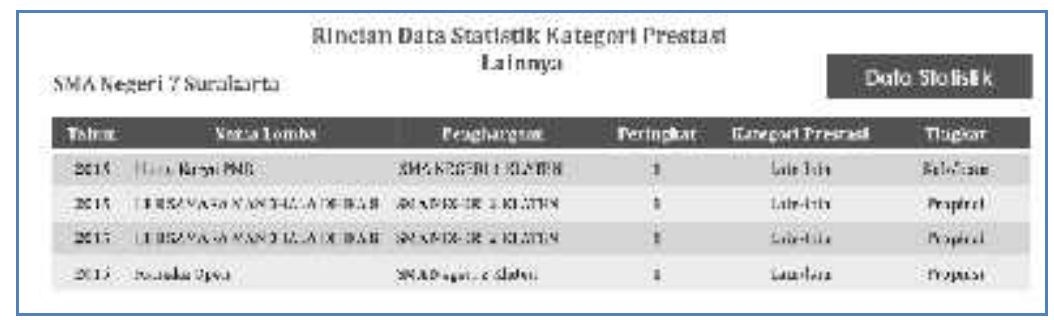

Gambar 14. Detail Data Prestasi

\section{KESIMPULAN}

Berdasarkan hasil pembahasan pada perancangan sistem kepakaran prestasi sekolah SMAN di kota Surakarta maka penulis dapat mengambil kesimpulan sebagai berikut:

1. Sistem kepakaran prestasi sekolah yang penulis rancang terdiri dari peta situs sistem kepakaran, framework pencarian, dan framework statistik prestasi.

2. Pada interface pencarian prestasi dapat menampilkan detail prestasi sekolah dan perbandingan prestasi dari beberapa sekolah yang dipilih, menampilkan detail tenaga pendidik dan menu untuk melihat atau mengunduh sertifikat akreditasi sekolah maupun sertifikat prestasi tenaga pendidik dan siswa.

3. Pada interface statistik dapat menampilkan grafik untuk mengetahui detail prestasi sesuai dengan kategori yang ingin ditampilkan maka akan menampilkan detail informasi prestasi.

4. Pada sistem kepakaran prestasi sekolah dapat dirancang basis data, yaitu membuat relasi tabel basis data sistem kepakaran, membuat suatu constrain foreign key agar inputan data yang saling berelasi tidak terjadi kesalahan dari sisi basis data, pembuatan trigger untuk menvalidasi inputan e-mail pada tabel pendidik dari sisi basis data, dan membuat role hak akses atau role access pengguna dalam mengakses basis data kepakaran sehingga keamanan data dapat diminimalisirkan jika terjadi adanya penyalahgunaan data yang tidak diinginkan.

5. Hasil sistem kepakaran prestasi sekolah diharapkan dapat membantu masyarakat untuk mengetahui informasi tentang suatu sekolah dan dapat dijadikan sebagai acuan dalam memberikan beasiswa kepada siswa dan tenaga pendidik serta untuk menentukan kandidat sebagai delegasi olimpiade sains dan teknologi.

\section{SARAN}

Penulisan makalah dalam penelitian ini adalah tentang perancangan sistem kepakaran prestasi sekolah untuk SMAN di Kota Surakarta. Adapun saran untuk penelitian selanjutnya adalah peneliti dapat merancang sebuah sistem kepakaran yang dikembangkan dengan penambahan fitur untuk dapat memilih sekolah negeri atau swasta serta dapat memilih jenjang sekolah mulai dari SD, SMP, SMA dan SMK yang ada di kota tertentu. Sedangkan dalam pengembangan basis data dapat dikembangkan dengan basis data posgreeSQL dan Oracle karena memiliki fitur yang lebih lengkap dari pada basis data $M y S Q L$.

\section{UCAPAN TERIMA KASIH}

Penulis mengucapkan terima kasih kepada Prof. Dr. Ema Utami, S.Si., M.Kom. dan Bapak Suwanto Raharjo, S.Si., M.Kom. serta Program Magister Teknik Informatika 
Universitas AMIKOM Yogyakarta karena telah membimbing dan membantu penulis dalam menyelesaikan makalah ini.

\section{DAFTAR PUSTAKA}

[1] Gat, 2015, Perancangan Basis Data Perputakaan Sekolah dengan Menerapkan Model Data Relasional, Citec Journal, Vol. 2, No. 4, hal 304-315.

[2] Slamet Riyanto, Lukman, dan Hendro Subagyo, 2011. Sistem Informasi Direktori Kepakaran Nasional Berbasis Web Sebagai Sarana Knowledge Management. Konferensi Teknologi dan Komunikasi untuk Indonesia, Bandung, 14-15 Juni 2011.

[3] Zakaria bin Taib, 2006, Penkelasan Kompetensi Bidang Kepakaran Berasaskan Rangkaian Neural Dalam Sistem Pengurusan Kompetensi, Fakulti Sains Komputer Dan Sistem Maklumat, Universiti Teknologi Malaysia, Kuala Lumpur.

[4] Abdurrakhman Prasetyadi dan D.W. Ari Nugroho, 2014, Kolaborasi Kepakaran Peneliti Pada Jurnal Ilmiah Lipi Bidang Informatika dan Kebumian, Visi Pustaka, Vol. 16, No. 1, hal 5-13.

[5] Muhammad Syafii dan Vidy, 2018, Kriptografi Monoalfabetik dan Polialfabetik Aplikasi dan Komparasi dalam Pengamanan Database Bank Soal,SEBATIK STMIK Wicida, ISSN.1410-3737, hal 1-9.

[6] Ema Utami dan Suwanto Raharjo, 2014, Database Security in The Academic Information System,International Journal of Security and Its Applications, Vol.8, No.3, hal 163-174.

[7] Storey, V.C. dan D. Dey, 2013, A Methodology for Learning Across Application Domains for Database Design Systems, IEEE Transactions on Knowledge and Data Engineering, vol. 14, No. 1, hal 13-28.

[8] Febria Sri Handayani dan Meidyan Permata Putri, 2017, Perancangan Basis Data Instrumen Bimbingan Konseling Alat Ungkap Pemahaman Diri Siswa, Citec Journal, Vol. 4, No. 2, hal 128-140.

[9] Dahlan Abdullah, Cut Yusra Novita dan Cut Ita Erliana, 2014, Perancangan Sistem Informasi Pengarsipan Pada Pdam Tirta Mon Pase Aceh Utara, Jurnal Ilmiah SISFOTENIKA, Vol. 4, No. 2, hal 95-104.

[10] Agus Wahyu Widodo, Diva Kurnianingtyas, 2017, Sistem Basis Data, UB Press, Malang. 